\title{
Effect of Acute Volume Loading on LV Function after Acute Cardiac Decentralization in Anesthetized Canines
}

\author{
John G. Kingma1, Denys Simard1,2, Jacques R. Rouleau ${ }^{1,2 *}$ \\ ${ }^{1}$ Department of Medicine, Université Laval, Québec, Canada \\ ${ }^{2}$ Centre de Recherche de I'Institut de Cardiologie et Pneumologie de Québec, Québec, Canada \\ Email: ${ }^{*}$ jrrouleau@gmail.com
}

Received 17 February 2016; accepted 9 April 2016; published 12 April 2016

Copyright (C) 2016 by authors and Scientific Research Publishing Inc.

This work is licensed under the Creative Commons Attribution International License (CC BY). http://creativecommons.org/licenses/by/4.0/

(c) (i) Open Access

\begin{abstract}
The present study investigated the role of cardiac nerves on homeometric autoregulation in anesthetized dogs during acute volume loading. Ventricular pressure-volume loops (conductance catheter method) were constructed during acute volume loading with intact cardiac nerves (ICN) and after cardiac decentralization (DCN; bilateral ablation of thoracic vagosympathetic complexes, stellate ganglia and anterior and posterior ansae subclavia). Arterial pressure increased as expected after volume loading but no significant changes were observed for heart rate and other hemodynamic parameters. Coronary sinus venous oxygen content was also higher regardless of nerve status in response to the overall increase in cardiac work. Pressure-volume catheter data showed markedly higher end-systolic volumes after volume loading under ICN and DCN conditions; stroke volume (mL/beat) and stroke work $(\mathrm{mL} / \mathrm{mm} \mathrm{Hg})$ were not changed but $\mathrm{LV}$ ejection fraction was significantly lower. End-diastolic volume and cardiac output did not change. In addition, systemic vascular resistance and tau were higher with volume loading but no differences between ICN and DCN were observed. These findings show that acute volume loading produces an immediate influence on $\mathrm{LV}$ function independent of cardiac nerve status.
\end{abstract}

\section{Keywords}

Extracardiac Nerves, Intrinsic Cardiac Neurons, Cardiac Decentralization, Left Ventricular Function

\section{Introduction}

The intrinsic cardiac nervous system regulates beat-to-beat coordination of regional cardiac function and inte-

*Corresponding author.

How to cite this paper: Kingma, J.G., Simard, D. and Rouleau, J.R. (2016) Effect of Acute Volume Loading on LV Function after Acute Cardiac Decentralization in Anesthetized Canines. World Journal of Cardiovascular Diseases, 6, 81-87. http://dx.doi.org/10.4236/wjcd.2016.64009 
grates both sympathetic and parasympathetic efferent activity [1]. Intrinsic neurons are activated by locally released endogenous chemicals [2] and are located within cardiac ganglionated plexi that project axons to different regions of the heart. While the importance of vagal and sympathetic nerves for regulation of ventricular function has been highlighted [3] [4] their role in homeometric autoregulation is not well established.

Homeometric autoregulation allows the LV to eject the same stroke volume against a wide range of resistances without increasing end-diastolic pressure and to increase contractility by reducing the duration of systole within the total cardiac cycle [5]. In hearts with intact cardiac nerves, stroke volume and work increase in relation to diastolic pressure or volume [3]. Impaired functionality of the autonomic nervous system could have negative effects on regulation of left ventricular (LV) volume and ventricular performance [6] [7]. For instance, in heart transplant patients LV volume regulation remains impaired even after normalization of cardiac hemodynamics while in heart failure patients, increased LV volume contributes to higher mortality [8].

Volume overload is frequently encountered in patients with co-morbidities (chronic kidney disease, heart failure, etc.) and is associated with adverse outcomes. The present study examined whether intact cardiac nerves contribute to homeometric autoregulation in anesthetized dogs during acute volume loading. LV pressure-volume loops were constructed using the conductance catheter method [9]. Experiments were performed in the same animal before and after acute bilateral ablation of extra-cardiac sympathetic and parasympathetic nerves (cardiac decentralization).

\section{Materials and Methods.}

\subsection{General Methods}

These studies were approved by the Laval University Animal Ethics Committee and were conducted in accordance with the Guide for the Care and Use of Experimental Animals (vols. 1 and 2) of the Canadian Council on Animal Care.

Healthy adult mongrel dogs of either gender, weighing 20 - $30 \mathrm{Kg}$ were fasted overnight, premedicated (Atravet, $0.5 \mathrm{mg} / \mathrm{Kg}$; IM) and then anesthetized with sodium pentobarbital (30 mg/kg, IV). Butorphanol tartrate (0.1 mg/Kg, IM) was administered for analgesia. After endotracheal intubation, dogs were ventilated with oxygen-enriched room air; respiratory rate and tidal volume were adjusted to maintain blood gases within physiological levels and atelectasis was prevented by maintaining end-expiratory pressure at $5-7 \mathrm{~cm} \mathrm{H}_{2} \mathrm{O}$. Normothermia $\left(38^{\circ} \mathrm{C} \pm 1^{\circ} \mathrm{C}\right.$ ) was maintained with a water-jacketed Micro-Temp heating blanket (Zimmer, Dover, $\mathrm{OH})$ and body temperature was monitored with a temperature probe in the trachea.

In the supine position, vascular introducer sheaths (8 Fr, Terumo Medical Corp., USA) were placed in the left and right femoral arteries; a triple-lumen central venous catheter (7 Fr, Arrow-Howes ${ }^{\mathrm{TM}}$, Arrow Intl. Inc., Reading, PA) was placed in the right femoral vein for administration of drugs and fluids.

A splenectomy was done through a mid-line abdominal incision as previously described [10] [11]; $450 \mathrm{~mL}$ of blood was then collected over 30-min in a $1 \mathrm{~L}$ heparinized flask containing $200 \mathrm{~mL}$ physiological saline. The abdominal cut-down was closed with surgical clips.

In the left lateral position, a thoracotomy was performed through the third and fifth intercostal spaces $\left(4^{\text {th }}\right.$ and $5^{\text {th }}$ ribs were removed to facilitate access to the extracardiac nerves). Left and right thoracic vagosympathetic complexes, left and right stellate ganglia and the anterior and posterior ansae subclavia were dissected free of surrounding tissues [12]. For cardiac decentralization, nerves were sectioned bilaterally as described earlier [13]; connective and neural tissues around the ascending aorta and left pulmonary artery and vein were not dissected (to preserve function of intrinsic cardiac neurons). Reflex control of cardiac function is mediated by complex interactions between peripheral and central neuronal elements [14]; transection of the ansae subclavia, vagosympathetic complexes and stellate ganglia eliminates the potentiating effects of the central nervous system on intrinsic cardiac neural activity.

The heart was exposed and suspended in a pericardial cradle. Catheters were inserted into the left atrium, the coronary sinus (for venous pressure measurements) and the pulmonary artery (for conductance catheter calibration). A 5Fr micro-tipped pressure transducer (MPC500; Millar Instruments Inc., Houston TX) was placed in the LV cavity through the apex to measure LV pressure and its first derivative; a 7Fr Pigtail catheter was advanced to the aortic root via the left femoral artery to measure arterial pressures. A 7 Fr, 12-electrode conductance catheter (CD Leycom, Zoetermeer, The Netherlands) was advanced via the femoral artery sheath and positioned 
at the LV apex along the longitudinal axis of the ventricle for construction of LV pressure-volume relations (LVPVR). After all catheters were positioned, dogs were given 500 IU heparin sodium intrvenously and allowed to stabilize for 30-min.

Left atrial, ascending aorta and coronary sinus catheters were connected to Statham P23Db strain gauge manometers; zero was set at mid-chest level. Millar micro-tipped pressure transducers were cross-calibrated with systolic aortic and diastolic left atrial pressures. All data were continuously recorded and stored on computer hard drive for later off-line analysis using AxoScope data acquisition software. The conductance catheter was calibrated using the hypertonic saline technique [15] and connected to a Sigma 5DF signal conditioning and processing unit; signals were acquired using Conduct NT software (version 3.8) and analysed off-line using Conduct NT software (Cardiodynamics, The Netherlands) [6].

\subsection{Experimental Protocol}

Under baseline conditions (i.e. Low) with intact cardiac nerves (ICN), LVPVR (ICN-Low) was constructed by acute vena caval occlusion for $\leq 12$-sec. After return to steady-state, $300 \mathrm{~mL}$ of diluted blood was infused into the left atrium over 5-min; with this intervention LV pressure increased $\sim 30 \mathrm{~mm} \mathrm{Hg}$. Upon return to steady state conditions a second LVPVR (ICN-High) was recorded.

After the first acute volume loading step, extracardiac nerves (i.e. stellate ganglia, ansae subclaviae and vagus) were excised bilaterally. The completeness of cardiac decentralization (DCN) was confirmed by the absence of heart rate and LV dynamics during direct electrical stimulation of the left and right ansae subclaviae $(10 \mathrm{~Hz}, 5$ ms, 5 - $7 \mathrm{~V})$ and the left and right thoracic vagi $(20 \mathrm{~Hz}, 5 \mathrm{~ms}, 5$ - $7 \mathrm{~V})$ [16]. An LVPVR was constructed under control (DCN-Low) conditions; $300 \mathrm{~mL}$ of diluted blood was then infused intra-atrially over 5-min, a second LVPVR (DCN-High) was recorded.

\subsection{Data and Statistical Analyses}

LV function data including stroke volume (SV; $\mathrm{mL}$ ), end-diastolic (EDV; $\mathrm{mL}$ ), end-systolic volume (ESV; $\mathrm{mL}$ ), stroke work (SW; $\mathrm{mL} \cdot \mathrm{mm} \mathrm{Hg}$ ) and LV ejection fraction (LVEF; \%-calculated as SV/EDV) were obtained using the conductance catheter. Differences in cardiac hemodynamics, blood gases and ventricular function were assessed by ANOVA. All statistical analyses were carried out using SAS software (SAS Institute Inc., Cary, NC, USA).

\section{Results}

\subsection{Blood Gases and Hemodynamic Changes}

As shown in Table 1, hematocrit levels were not changed by volume loading either in the setting of ICN or after DCN. Arterial oxygen and carbon dioxide levels were not different; significant lowering of coronary sinus venous oxygen content occurred after volume loading in both experimental groups probably due to the increase in cardiac work.

Arterial pressure increased as expected considering the experimental model; no change was observed for coronary sinus pressures (cf. Table 2). A similar profile was observed in animals with ICN and after DCN. Additionally, heart rate was stable throughout the experimental protocols.

\subsection{Performance Findings}

End-systolic volume increased markedly after volume loading under ICN and DCN conditions (cf. Table 3); stroke volume with ICN (12 \pm 4 vs $10 \pm 4 \mathrm{~mL} /$ beat) and DCN (11 \pm 4 vs $10 \pm 2 \mathrm{~mL} /$ beat $)$ did not change. Stroke work was also unaffected with ICN (739 \pm 328 vs $718 \pm 286 \mathrm{~mL} / \mathrm{mm} \mathrm{Hg}$ ) and after DCN (619 \pm 264 vs $712 \pm$ $201 \mathrm{~mL} / \mathrm{mm} \mathrm{Hg}$ ) before, and after volume loading, respectively. LV ejection fraction also decreased significantly with volume loading in both experimental groups. No change was observed for end-diastolic volume or cardiac output. Systemic vascular resistance increased with volume loading; however, no differences were seen between ICN and DCN $(0.150 \pm 0.067$ vs. $0.134 \pm 0.048 \mathrm{~mm} \mathrm{Hg} / \mathrm{mL})$. Significant increases in tau, the time constant of LV relaxation, were observed and after volume loading in both experimental groups. The slope of the end-systolic pressure-volume relation, $\left(E_{\text {es }}\right)$ was not altered after $D C N$; representative pressure-volume loops are shown (Figure 1). 


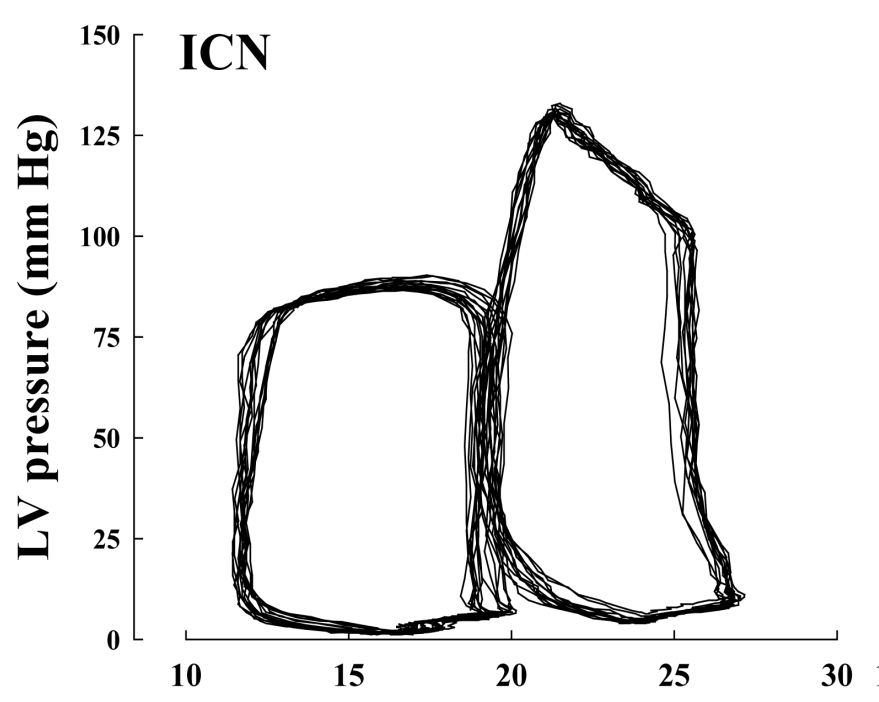

\section{DCN}

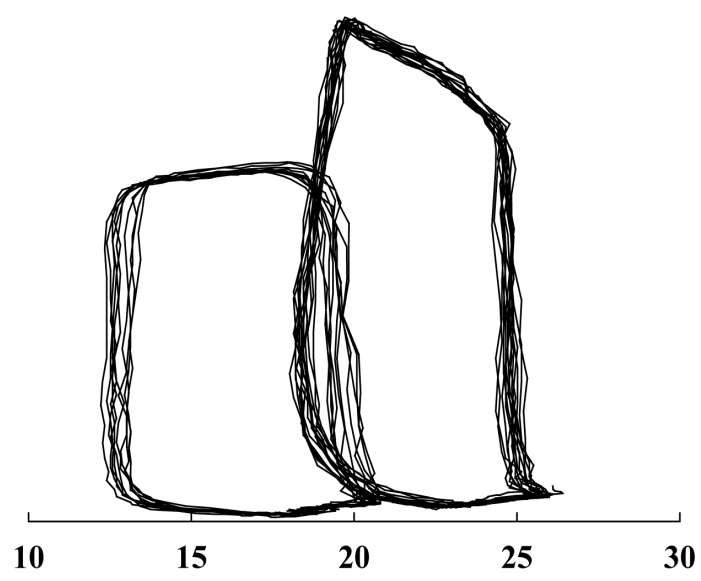

\section{LV volume (mL)}

Figure 1. Representative plot showing LV pressure-volume loops recorded before and after acute volume loading from an animal with intact cardiac nerves (ICN; left panel) and after cardiac decentralization (DCN; right panel).

Table 1. Summary of blood gases and oxygen contents.

\begin{tabular}{|c|c|c|c|c|c|c|c|c|c|c|}
\hline & \multicolumn{2}{|c|}{ Hct } & \multicolumn{2}{|c|}{$\mathrm{PaO}_{2}$ tension } & \multicolumn{2}{|c|}{$\mathrm{PaCO}_{2}$ tension } & \multicolumn{2}{|c|}{$\mathrm{AO}_{2}$ content } & \multicolumn{2}{|c|}{$\mathrm{CSO}_{2}$ content } \\
\hline & INN & DCN & INN & DCN & INN & DCN & INN & DCN & INN & DCN \\
\hline Low & $32 \pm 5$ & $31 \pm 4$ & $134 \pm 34$ & $130 \pm 32$ & $43 \pm 8$ & $45 \pm 13$ & $12.7 \pm 1.2$ & $13.2 \pm 1.0$ & $5.8 \pm 0.4$ & $6.2 \pm 0.7$ \\
\hline High & $30 \pm 4$ & $29 \pm 5$ & $143 \pm 48$ & $132 \pm 36$ & $43 \pm 10$ & $46 \pm 14$ & $12.2 \pm 0.9$ & $12.1 \pm 1.0$ & $4.8 \pm 0.8$ & $4.9 \pm 0.9$ \\
\hline$p$ DCN & \multicolumn{2}{|c|}{ NS } & \multicolumn{2}{|c|}{ NS } & \multicolumn{2}{|c|}{ NS } & \multicolumn{2}{|c|}{ NS } & \multicolumn{2}{|c|}{ NS } \\
\hline$p$ High & \multicolumn{2}{|c|}{ NS } & \multicolumn{2}{|c|}{ NS } & \multicolumn{2}{|c|}{ NS } & \multicolumn{2}{|c|}{ NS } & \multicolumn{2}{|c|}{0.03} \\
\hline$p$ Inter & \multicolumn{2}{|c|}{ NS } & \multicolumn{2}{|c|}{ NS } & \multicolumn{2}{|c|}{ NS } & \multicolumn{2}{|c|}{ NS } & \multicolumn{2}{|c|}{ NS } \\
\hline
\end{tabular}

Data are mean $\pm 1 \mathrm{SD}$. Hct (volume \%): hematocrit; $\mathrm{PaO}_{2}, \mathrm{PaCO}_{2}$ (mm Hg): arterial oxygen, carbon dioxide tension; $\mathrm{AO}_{2}$ content, $\mathrm{CSO}_{2}$ content $(\mathrm{mL} / \mathrm{mL})$ : arterial, coronary sinus oxygen content. P values were obtained from ANOVA with repeated-measures analyses; Student-Newman-Keuls multiple range test was performed on main-effect means to identify differences between interventions.

Table 2. Summary of cardiac hemodynamics and heart rate.

\begin{tabular}{|c|c|c|c|c|c|c|c|c|c|c|}
\hline & \multicolumn{2}{|c|}{ HR } & \multicolumn{2}{|c|}{$\mathbf{P A o}_{\text {sys }}$} & \multicolumn{2}{|c|}{$\mathbf{P A o}_{\text {dias }}$} & \multicolumn{2}{|c|}{$\mathrm{CSP}_{\text {sys }}$} & \multicolumn{2}{|c|}{$\mathbf{C S P}_{\text {dias }}$} \\
\hline & INN & DCN & INN & DCN & INN & DCN & INN & DCN & INN & DCN \\
\hline Low & $108 \pm 14$ & $104 \pm 10$ & $97 \pm 11$ & $94 \pm 13$ & $67 \pm 8$ & $65 \pm 8$ & $8 \pm 4$ & $7 \pm 3$ & $3 \pm 1$ & $3 \pm 2$ \\
\hline High & $107 \pm 13$ & $106 \pm 10$ & $135 \pm 12$ & $136 \pm 12$ & $90 \pm 3$ & $88 \pm 6$ & $9 \pm 5$ & $9 \pm 5$ & $4 \pm 3$ & $3 \pm 2$ \\
\hline$p$ DCN & \multicolumn{2}{|c|}{ NS } & \multicolumn{2}{|c|}{ NS } & \multicolumn{2}{|c|}{ NS } & \multicolumn{2}{|c|}{ NS } & \multicolumn{2}{|c|}{ NS } \\
\hline$p$ High & \multicolumn{2}{|c|}{ NS } & \multicolumn{2}{|c|}{0.001} & \multicolumn{2}{|c|}{0.001} & \multicolumn{2}{|c|}{ NS } & \multicolumn{2}{|c|}{ NS } \\
\hline$p$ Inter & \multicolumn{2}{|c|}{ NS } & \multicolumn{2}{|c|}{ NS } & \multicolumn{2}{|c|}{ NS } & \multicolumn{2}{|c|}{ NS } & \multicolumn{2}{|c|}{ NS } \\
\hline
\end{tabular}

Data are mean \pm 1 SD. HR (beats per minute): heart rate; $\mathrm{PAo}_{\text {sys }}, \mathrm{PAo}_{\text {dias }}(\mathrm{mm} \mathrm{Hg})$ : systolic, diastolic arterial pressure; $\mathrm{CSP}_{\mathrm{sys}}, \mathrm{CSP}_{\text {dias }}(\mathrm{mm} \mathrm{Hg}): ~ s y s-$ tolic, diastolic coronary sinus pressure. $\mathrm{P}$ values were obtained from ANOVA with repeated-measures analyses; Student-Newman-Keuls multiple range test was performed on main-effect means to identify differences between interventions. 
Table 3. Summary of LV pressure-volume data.

\begin{tabular}{|c|c|c|c|c|c|c|c|c|c|c|c|c|}
\hline & \multicolumn{2}{|c|}{ ESV } & \multicolumn{2}{|c|}{ EDV } & \multicolumn{2}{|c|}{ CO } & \multicolumn{2}{|c|}{ Tau } & \multicolumn{2}{|c|}{$\mathbf{E}_{\text {es }}$} & \multicolumn{2}{|c|}{ EF } \\
\hline & INN & DCN & INN & DCN & INN & DCN & INN & DCN & INN & DCN & INN & DCN \\
\hline Low & $13 \pm 3$ & $12 \pm 6$ & $24 \pm 8$ & $22 \pm 9$ & $1.02 \pm 0.46$ & $0.81 \pm 0.35$ & $33.2 \pm 4.4$ & $33.8 \pm 5.0$ & $3.7 \pm 0.3$ & $3.8 \pm 1.0$ & $41 \pm 2$ & $40 \pm 12$ \\
\hline High & $18 \pm 7$ & $19 \pm 9$ & $27 \pm 10$ & $28 \pm 11$ & $0.72 \pm 0.37$ & $0.71 \pm 0.20$ & $38.6 \pm 3.7$ & $41.8 \pm 4.3$ & $3.9 \pm 1.2$ & $4.1 \pm 1.6$ & $26 \pm 8$ & $28 \pm 7$ \\
\hline$p$ DCN & \multicolumn{2}{|c|}{ NS } & \multicolumn{2}{|c|}{ NS } & \multicolumn{2}{|c|}{ NS } & \multicolumn{2}{|c|}{ NS } & \multicolumn{2}{|c|}{ NS } & \multicolumn{2}{|c|}{ NS } \\
\hline$p$ High & \multicolumn{2}{|c|}{0.05} & \multicolumn{2}{|c|}{ NS } & \multicolumn{2}{|c|}{ NS } & \multicolumn{2}{|c|}{0.04} & \multicolumn{2}{|c|}{ NS } & \multicolumn{2}{|c|}{0.002} \\
\hline$p$ Inter & \multicolumn{2}{|c|}{ NS } & \multicolumn{2}{|c|}{ NS } & \multicolumn{2}{|c|}{ NS } & \multicolumn{2}{|c|}{ NS } & \multicolumn{2}{|c|}{ NS } & \multicolumn{2}{|c|}{ NS } \\
\hline
\end{tabular}

Data are mean \pm 1 SD. ESV, EDV (mL): end-systolic, end-diastolic volume; CO (L/min): cardiac output; Tau (ms): time constant of LV relaxation; $\mathrm{E}_{\mathrm{es}}(\mathrm{mm} \mathrm{Hg} / \mathrm{mL})$ : slope of the end-systolic LVPVR; EF (\%): LV ejection fraction. P values were obtained from ANOVA with repeated-measures analyses; Student-Newman-Keuls multiple range test was performed on main-effect means to identify differences between interventions.

\section{Discussion}

Adequacy of blood circulation is, for the most part, coordinated through the autonomic nervous system which innervates the heart and vascular system. Neural control mechanisms play a dominant role in the heart's adaptive responsiveness to different stressors. The present study examined the effect of acute volume loading on left ventricular function in dogs with intact extra-cardiac nerves and after acute cardiac decentralization. In the presence of intact cardiac nerves, acute after load augmentation prolonged isovolumetric myocardial relaxation, increased arterial pressures and end-systolic ventricular volumes without changing cardiac output. Ventricular ejection fraction was also significantly lower after volume loading; the reduction in venous oxygen content suggests increased oxygen uptake in relation to cardiac work. Acute cardiac decentralization does not appear to further modulate direct effects of volume loading on LV function and suggests that the activation of non-neural factors is principally responsible for induction of early changes in LV function.

In normal subjects, neurohormonal mechanisms regulate water and sodium balance; activation of these mechanisms increases workload and can result in decreased cardiac function [17] and even survival [18] [19] particularly in the presence of ongoing cardiovascular disease [20]. Clinical management of patients with volume overload is a particular challenge considering multiple presentations and associated comorbidities (see review by Chen and Schrier [21]). The rationale for volume loading in the clinic is to increase cardiac preload and cardiac output in order to improve organ perfusion and post-surgery outcomes in patients. With volume loading arterial and cardiopulmonary mechanoreceptors exercise a tonic inhibitory influence on sympathetic efferent outflow [22]; pressure mechanoreceptors also modulate sympathetic efferent and parasympathetic outflow. In comparison with the normal heart, the denervated heart responds to a higher cardiac output requirement by substantially increasing stroke volume with a minimal increase in heart rate [23] [24]. Reduced regulation of volume status can exacerbate cardiac symptoms. Multiple changes in the renin-angiotensin-aldosterone system, arginine vasopressin and sympathetic nervous system also produce changes in volume management and cardiac output that lead to impaired cardiac output. The inability to conserve normal volume causes neurohormonal activation which worsens volume overload and affects cardiac remodeling and disease progression. Activation of natriuretic peptides can also stimulate relaxation of vascular smooth muscle thereby lower blood pressure and ventricular preload [25] [26]. These peptides have been shown to stimulate intrinsic cardiac neurons and modulate ventricular function [27] [28].

Study limitations. Certain methodological limitations for the present study are acknowledged. Dogs were ventilated using a positive-pressure respirator since tolerance to rapid infusions of electrolyte solution has been reported to be greater compared to animals breathing spontaneously [29]. Data were recorded about 10-min after completion of volume loading to better reflect systemic responses induced by overload rather than hemodynamic changes that could be produced by the fluid pump. The influences of non-neural mechanisms (intramyocardial tissue and LV cavity pressures, LV wall stiffness, ventricular blood flow) that contribute to ventriculoarterial coupling were not considered here since they have previously been examined in earlier animal studies [30] [31] [32]. 


\section{Conclusion}

In summary, volume overload is a complex pathologic process that presents significant diagnostic challenges. In the study reported here, we document that the effects of acute volume loading on regulation of LV function were not markedly affected by ablation of extra-cardiac nerves. Our findings suggest that non-neural factors initiate early adaptation of LV function in the setting of acute volume overload. While these findings are interesting, any attempt to extrapolate these data to chronic volume overload or other associated pathologies is speculative. Future investigations that focus on evaluation of volume loading in the presence of co-morbidities or any-cause chronic neuropathy may help to improve understanding of underlying mechanisms and development of effective treatment strategies.

\section{Funding}

This study was funded by a generous contribution from the Laboratoire expérimental de physiologie coronarienne Paul Jalbert at the Institut universitaire de cardiologie et pneumologie-Université Laval.

\section{Conflict of Interest}

There are no conflicts of interest to disclose for this study.

\section{References}

[1] Armour, J.A. (2008) Potential Clinical Relevance of the "Little Brain” on the Mammalian Heart. Experimental Physiology, 93, 165-176. http://dx.doi.org/10.1113/expphysiol.2007.041178

[2] Girasole, A.E., Palmer, C.P., Corrado, S.L., Marie, S.E., Ardell, J.L. and Hardwick, J.C. (2011) Angiotensin II Potentiates Adrenergic and Muscarinic Modulation of Guinea Pig Intracardiac Neurons. American Journal of Physiology. Regulatory, Integrative and Comparative Physiology, 301, R1391-R1399. http://dx.doi.org/10.1152/ajpregu.00145.2011

[3] Donald, D.E. and Shepherd, J.T. (1963) Response to Exercise in Dogs with Cardiac Denervation. American Journal of Physiology, 205, 393-400.

[4] Sarnoff, S.J., Brockman, S.K., Gilmore, J.P., Linden, R.J. and Mitchell, J.H. (1960) Regulation of Ventricular Contraction. Influence of Cardiac Sympathetic and Vagal Nerve Stimulation on Atrial and Ventricular Dynamics. Circulation Research, 8, 1108-1122. http://dx.doi.org/10.1161/01.RES.8.5.1108

[5] Sarnoff, S.J., Mitchell, J.H., Gilmore, J.P. and Remensnyder, J.P. (1960) Homeometric Autoregulation in the Heart. Circulation Research, 8, 1077-1091. http://dx.doi.org/10.1161/01.RES.8.5.1077

[6] Baan, J., Van der Velde, E.T. and Steendijk, P. (1992) Ventricular Pressure-Volume Relations in Vivo. European Heart Journal, 13, 2-6. http://dx.doi.org/10.1093/eurheartj/13.suppl_E.2

[7] Braith, R.W., Mills Jr., R.M., Wilcox, C.S., Davis, G.L. and Wood, C.E. (1996) Breakdown of Blood Pressure and Body Fluid Homeostasis in Heart Transplant Recipients. Journal of the American College of Cardiology, 27, 375-383. http://dx.doi.org/10.1016/0735-1097(95)00467-X

[8] Androne, A.S., Hryniewicz, K., Hudaihed, A., Mancini, D., Lamanca, J. and Katz, S.D. (2004) Relation on Unrecognized Hypervolemia in Chronic Heart Failure to Clinical Status, Hemodynamics, and Patient Outcomes. American Journal of Cardiology, 93, 1254-1259. http://dx.doi.org/10.1016/j.amjcard.2004.01.070

[9] Baan, J., van der Velde, E., de Bruin, H.G., Smeenk, G.J., Koops, J., van Dijk, A., Temmerman, D., Senden, J. and Buis, B. (1984) Continuous Measurement of Left Ventricular Volume in Animls and Humans by Conductance Catheter. Circulation, 70, 812-823. http://dx.doi.org/10.1161/01.CIR.70.5.812

[10] Huang, A.H. and Feigl, E.O. (1988) Adrenergic Coronary Vasoconstriction Helps Maintain Uniform Transmural Blood Flow Distribution during Exercise. Circulation Research, 62, 286-298. http://dx.doi.org/10.1161/01.RES.62.2.286

[11] Sato, N., Shen, Y.-T., Kiuchi, K., Shannon, R.P. and Vatner, S.F. (1995) Splenic Contraction-Induced Increases in Arterial O2 Reduce Requirement for CBF in Conscious Dogs. American Journal of Physiology (Heart and Circulatory Physiology), 269, H491-H503.

[12] Ardell, J.L., Butler, C.K., Smith, F.M., Hopkins, D.A. and Armour, J.A. (1991) Activity of in Vivo Atrial and Ventricular Neurons in Chronically Decentralized Canine Hearts. American Journal of Physiology (Heart and Circulatory Physiology), 260, H713-H721.

[13] Rouleau, J.R., Simard, D., Rodrigue, N., Blouin, A. and Kingma Jr., J.G. (2002) Myocardial Blood Flow after Chronic Cardiac Decentralization in Anesthetized Dogs: Effects of ACE-Inhibition. Autonomic Neuroscience, 97, 12-18. 
http://dx.doi.org/10.1016/S1566-0702(02)00002-4

[14] Ardell, J.L., Cardinal, R., Vermeulen, M. and Armour, J.A. (2009) Dorsal Spinal Cord Stimulation Obtunds the Capacity of Intrathoracic Extracardiac Neurons to Transduce Myocardial Ischemia. American Journal of Physiology - Regulatory, Integrative and Comparative Physiology, 297, R470-R477. http://dx.doi.org/10.1152/ajpregu.90821.2008

[15] Van der Velde, E.T., Burkhoff, D., Steendijk, P., Karsdon, J., Sagawa, K. and Baan, J. (1991) Nonlinearity and Load Sensitivity of End-Systolic Pressure-Volume Relation of Canine Left Ventricle in Vivo. Circulation, 83, 315-327. http://dx.doi.org/10.1161/01.CIR.83.1.315

[16] Lavallee, M., Amano, J., Vatner, S.F., Manders, W.T., Randall, W.C. and Thomas Jr., J.X. (1985) Adverse Effects of Chronic Cardiac Denervation in Conscious Dogs with Myocardial Ischemia. Circulation Research, 57, 383-392. http://dx.doi.org/10.1161/01.RES.57.3.383

[17] Hori, Y., Kunihiro, S., Hoshi, F. and Higuchi, S. (2007) Comparison of the Myocardial Performance Index Derived by Use of Pulsed Doppler Echocardiography and Tissue Doppler Imaging in Dogs with Volume Overload. American Journal of Veterinary Research, 68, 1177-1182. http://dx.doi.org/10.2460/ajvr.68.11.1177

[18] Hohnloser, S.H., Klingenheben, T., van de Loo, A., Hablawetz, E., Just, H. and Schwartz, P.J. (1994) Reflex versus Tonic Vagal Activity as a Prognostic Parameter in Patients with Sustained Ventricular Tachycardia or Ventricular Fibrillation. Circulation, 89, 1068-1073. http://dx.doi.org/10.1161/01.CIR.89.3.1068

[19] Osterziel, K.J., Hanlein, D., Willenbrock, R., Eichhorn, C., Luft, F. and Dietz, R. (1995) Baroreflex Sensitivity and Cardiovascular Mortality in Patients with Mild to Moderate Heart Failure. British Heart Journal, 73, 517-522. http://dx.doi.org/10.1136/hrt.73.6.517

[20] Shotan, A., Dacca, S., Shochat, M., Kazatsker, M., Blondheim, D.S. and Meisel, S. (2005) Fluid Overload Contributing to Heart Failure. Nephrology Dialysis Transplantation, 20, vii24-vii27. http://dx.doi.org/10.1093/ndt/gfh1103

[21] Chen, H.H. and Schrier, R.W. (2006) Pathophysiology of Volume Overload in Acute Heart Failure Syndromes. The American Journal of Medicine, 119, S11-S16. http://dx.doi.org/10.1016/j.amjmed.2006.09.012

[22] Hainsworth, R. (1991) Reflexes from the Heart. Physiological Reviews, 71, 617-658.

[23] Guyton, R.A., Bianco, J.A., Ostheimer, G.W., Shanahan, E.A. and Daggett, W.M. (1972) Adrenergic Control of Ventricular Performance in Normal and Cardiac-Denervated Dogs. American Journal of Physiology, 223, 1021-1028.

[24] Stone, H.L., Bishop, V.S. and Dong Jr., E. (1967) Ventricular Function in Cardiac-Denervated and Cardiac-Sympathectomized Conscious Dogs. Circulation Research, 20, 587-593. http://dx.doi.org/10.1161/01.RES.20.6.587

[25] de Lemos, J.A., McGuire, D.K. and Drazner, M.H. (2003) B-Type Natriuretic Peptide in Cardiovascular Disease. Lancet, 362, 316-322. http://dx.doi.org/10.1016/S0140-6736(03)13976-1

[26] Tonolo, G., Richards, A.M., Manunta, P., Troffa, C., Pazzola, A., Madeddu, P., Towrie, A., Fraser, R. and Glorioso, N. (1989) Low-Dose Infusion of Atrial Natriuretic Factor in Mild Essential Hypertension. Circulation, 80, 893-902. http://dx.doi.org/10.1161/01.CIR.80.4.893

[27] Armour, J.A. (1989) Peptidergic Modulation of Efferent Sympathetic Neurons in Intrathoracic Ganglia Regulating the Canine Heart. Proceedings of the Society for Experimental Biology and Medicine, 191, 60-68. http://dx.doi.org/10.3181/00379727-191-42890

[28] Armour, J.A., Yuan, B. and Butler, C.K. (1990) Cardiac Responses Elicited by Peptides Administered to Canine Intrinsic Cardiac Neurons. Peptides, 11, 753-761. http://dx.doi.org/10.1016/0196-9781(90)90191-7

[29] Johnson Jr., G. and Lambert, J. (1968) Responses to the Rapid Intravenous Administration of an Overload of Fluid and Electrolytes in Dogs. Annals of Surgery, 167, 561-567. http://dx.doi.org/10.1097/00000658-196804000-00013

[30] Krams, R., Sipkema, P., Zegers, J. and Westerhof, N. (1989) Contractility Is the Main Determinant of Coronary Systolic Flow Impediment. American Journal of Physiology, 257, H1936-H1944.

[31] Rouleau, J.R., Simard, D. and Kingma Jr., J.G. (1999) Myocardial Blood Flow Regulation Relative to Left Ventricle Pressure and Volume in Anesthetized Dogs. Canadian Journal of Physiology and Pharmacology, 77, 902-908. http://dx.doi.org/10.1139/y99-100

[32] Spaan, J.A. (1985) Coronary Diastolic Pressure-Flow Relation and Zero Flow Pressure Explained on the Basis of Intramyocardial Compliance. Circulation Research, 56, 293-309. http://dx.doi.org/10.1161/01.RES.56.3.293 